\title{
Irrigation Frequency and Amount Effect on Root Extension during Sod Establishment of Warm-season Grasses
}

\author{
Thomas R. Sinclair ${ }^{1}$ and Andrew Schreffler \\ Agronomy Department, University of Florida, Gainesville, FL 32611 \\ Benjamin Wherley \\ Texas AgriLife Research Urban Solutions Center, Dallas, TX 75252
}

Michael D. Dukes

Department of Agricultural and Biological Engineering, University of Florida, Gainesville, FL 32611

Additional index words. bahiagrass, bermudagrass, St. Augustine, root mass, zoysiagrass

\begin{abstract}
Although root development is critical in the establishment of turfgrass sod, there appears to be no information on the response of root development during sod establishment to the frequency and amount of irrigation. Two alternate hypotheses for the root development response are that 1) frequent and high amounts of irrigation are needed to support sod growth and root development; and 2) deficit irrigation encourages more rapid and deeper rooting. The objective of this study was to observe root development of four warm-season turfgrasses subjected to various frequencies and amounts of irrigation. Root extension of the grasses was observed directly in soil contained in $90-\mathrm{cm}$ tall, clear acrylic columns. No difference in root development was observed for any of the grasses among irrigation frequency treatments of daily, twice weekly, and once weekly. There were differences in response to the amount of irrigation. Zoysiagrass root development was maximal at the full amount of irrigation $(35 \mathrm{~mm}$ per week). On the other hand, St. Augustinegrass, bermudagrass, and bahiagrass required deficit irrigation of only $13 \mathrm{~mm}$ water per week to achieve full root development. The results of this study showed that each of the two hypotheses were appropriate depending on the specific species.
\end{abstract}

A key aspect in the establishment of turfgrass sod is rapid rooting or "knitting" of the sod into the underlying soil. Factors that ensure rapid sod rooting include 1) proper soil aeration; 2) adequate moisture in the underlying soil; and 3) transplanting techniques that minimize desiccation (Beard, 1973). Rapid root extension into the soil is essential to gain access to water and nutrients to support the establishment of the sod plants. Therefore, understanding the impact of various management options, including irrigation, is crucial to maximize success in sod establishment.

Irrigation management options include both the frequency and amount of irrigation. Beard (1973) recommended irrigating newly laid sod lightly on a daily basis to maintain adequate moisture level in the sod with thickcut sod requiring less frequent irrigation than thin sod; however, research is lacking that examines the direct relationship between sod root establishment and irrigation frequency or volume. There are alternative speculations about the impact of irrigation on root exten-

Received for publication 7 Apr. 2011. Accepted for publication 2 June 2011.

We thank the Southwest Florida Water Management District and the Florida Agricultural Experiment Station for support of this research.

${ }^{1}$ To whom reprint requests should be addressed; e-mail trsincl@ifas.ufl.edu. sion in establishing sod. One hypothesis is that frequent irrigations with large amounts of water are needed to encourage rapid root growth, although there is the possibility that such intense irrigation could discourage deep rooting into the soil. A second hypothesis is that infrequent irrigations and/or deficit irrigations stimulate rapid root extension to reach layers deep in the soil that might contain stored water. Although deficit irrigation during establishment could be beneficial in terms of water conservation, it may also negatively impact shoot growth and sod establishment.

Surprisingly, virtually no information appears to have been obtained on root extension of turfgrasses during turf sod establishment. Studies on temporal changes in root populations of established sod subject to various irrigation regimes may offer some guidance about root response to various irrigation regimes during establishment. In a study of established sod of five warm-season grasses, Doss et al. (1960) found that rooting depth was decreased for all species as the amount of water applied was increased. Qian and Fry (1996) examined the effect on water extraction by zoysiagrass (Zoysia japonica Steud.) only after sod had grown for $107 \mathrm{~d}$ in $92-\mathrm{cm}$ deep cylinders. Two irrigation regimes (daily and at leaf rolling) were then applied to this established sod. Infrequent irrigation resulted in greater water extraction and presumably as a result of additional root growth at 55- and 75-cm depths as compared with daily irrigation. The root mass of zoysiagrass was found to be positively associated with drought survival (Marcum et al., 1995). Rooting of tall fescue (Festuca arundinacea) by established sod in response to differing amounts of water application $(20 \%, 60 \%$, and $100 \%$ evapotranspiration) applied twice weekly was viewed directly with mini-rhizotrons (Fu et al., 2007). Deficit irrigation tended to result in greater numbers of roots at the end of the growing season (August and September) than in plots watered to replenish $100 \%$ evapotranspiration. Fu and Dernoeden (2009) also used mini-rhizotrons to document that infrequent irrigation of creeping bentgrass (Agrosis stolonifera L.) resulted in more roots and greater root lengths than the treatment of daily irrigation. Overall, these studies with established sods indicate that rooting depth is stimulated by limiting the frequency or amount of water application.

A critical unresolved issue is the impact of restricted irrigation on root extension during the critical time of sod establishment. The objective of this work was to provide information on root extension of four warm-season grasses during sod establishment. Root extension was observed by sod establishing on soil columns in clear acrylic tubes. Based on studies of previous investigations with established sods, the hypothesis to be resolved is that water deficit either by infrequent irrigation intervals or amount of irrigation results in increased root growth.

\section{Materials and Methods}

Root development was observed for the most commercially important cultivar of each of four turfgrasses: cv. Argentine bahiagrass (Paspalum notatum), cv. Tifway 419 bermudagrass (Cynodon dactylon), cv. Floratam St. Augustinegrass (Stenotaphrum secundatum (Walt) Kuntze), and cv. Empire zoysiagrass. For the remainder of this article, the plant material is referred to by species. However, it should be noted that cultivar variations are certainly possible within a species and species designations may need to be reassessed in view of results with additional cultivars.

Sod was placed on soil columns contained in $10-\mathrm{cm}$ diameter, $95-\mathrm{cm}$ tall, clear acrylic cylinders (Acuna et al., 2010). The top of the tubes had been painted white so that light was not transmitted to the root zone within the tube walls. A hole in the bottom cap of the cylinders allowed drainage of excess water from the columns.

The tubes were filled with loamy sand (Tavares sand, hyperthermic, Typic Quartzpsamment, Entisol) collected at the University of Florida Plant Science Research and Education Unit (PSREU), Citra, FL. The soil was fully wetted by repeated watering of the soil. The tubes were placed in large boxes to maintain the root zone in the dark and only the top part of the tubes extended out of the top of the boxes. One side of the boxes could be swung open to facilitate the measurements of root development. Four boxes, each 
containing 12 soil columns, were grouped together in an open-sided greenhouse (Gainesville, FL) to prevent rain from reaching the columns. Each box represented a replicate block containing three irrigation treatments of each of the four grasses positioned randomly.

After the soil was fully watered, $10-\mathrm{cm}$ diameter circular sod pieces were collected from established sod plots of each grass at PSREU using a golf cup cutter. The sod pieces with a $5-\mathrm{cm}$ thick layer of rhizosphere were placed on the soil columns and fully watered. Thereafter for the remainder of the establishment period, various irrigation treatments were imposed. Three times per week (Monday, Wednesday, and Friday), the position of the deepest visible root in each column was recorded. Observations were continued over 5 weeks, which in most cases allowed the roots to reach the bottom of the columns. Linear regressions of depth versus $d$ of observations were performed for each column (Acuna et al., 2010). Mean extension rate was calculated for the four replicate columns of each treatment and grass.

Once the roots of each species had either stopped growing or had reached the bottom of the columns, the roots were harvested to document the dry weight that developed for each grass at various depths. Intact soil columns were removed from the acrylic tubes and cut into four segments: 0 to $5 \mathrm{~cm}, 5$ to $30 \mathrm{~cm}$, 30 to $60 \mathrm{~cm}$, and 60 to $90 \mathrm{~cm}$. The top segment of 0 to $5 \mathrm{~cm}$ that constituted the original sod piece placed on the column was discarded. The soil for the three remaining segments was carefully washed to remove the roots. The roots were dried in a $60^{\circ} \mathrm{C}$ oven for at least $3 \mathrm{~d}$ and then weighed.

The first experiment (Expt. 1) was initiated on 22 Mar. 2010 to study the influence of frequency of irrigation on root development. Three frequencies of irrigation were applied: daily, twice weekly, and once weekly. The total amount of irrigation for all columns on a weekly basis was $280 \mathrm{~mL}$ water per column, or the equivalent of $35 \mathrm{~mm}$ per week. This volume of irrigation corresponds to a typical springtime evapotranspiration water loss on bright days by warm-season grasses in Florida (Jia et al., 2009). Therefore, the amount of water application in each treatment returned the soil to a well-watered condition.

The second and third experiments (Expts. 2 and 3) examined the influence of the amount of irrigation on root development. In these experiments, columns were refilled and sod pieces were placed on the soil columns on 7 June 2010 and on 23 Aug. 2010, respectively. All columns were fully watered immediately after placing the fresh sod pieces on the soil columns. Three d later the first irrigation of each weekly watering treatment was applied. The three treatments were water applications of $280 \mathrm{~mL}$ water (equivalent to a water depth of $35 \mathrm{~mm}), 105 \mathrm{~mL}$ (13 mm), or $35 \mathrm{~mL}$ (4 mm). Subsequently, the columns were watered at weekly intervals maintaining the irrigation treatment for each column. The two lowest irrigation rates were designed to result in the development of water-deficit stress.
In all experiments, the grasses were clipped once a week if there had been sufficient growth to warrant clipping. The grasses were clipped to a height of $5 \mathrm{~cm}$ for zoysiagrass and bermudagrass and $7.6 \mathrm{~cm}$ for bahiagrass and St. Augustinegrass. In Expt. 3, the clippings were collected, dried in a $60^{\circ} \mathrm{C}$ oven for at least $3 \mathrm{~d}$, and then weighed.

Differences between treatments for the measured variables were tested using the Newman-Keuls multiple comparison test that is provided in Prism Version 2.01 (GraphPad Software Inc., San Diego, CA). Significant differences were identified for $P<0.05$.

\section{Results}

Root extension rate. The regression of depth versus $d$ of observation for each column was highly linear in all cases. The $\mathrm{CV}\left(r^{2}\right)$ for individual columns was greater than 0.85 for nearly all columns, and commonly $r^{2}$ was greater than 0.90 . These results demonstrated that root extension rate was constant throughout this establishment period of all grasses in all experiments.

The results from Expt. 1, which compared frequencies of irrigation, demonstrated substantial consistency among replications in root extension rate within a species and treatment as illustrated by the small SE of the mean (Fig. 1). Within a species, there was no significant difference in the rate of root extension (slope of the linear regression) (Fig. 1). However, there were differences in root extension rate among species. Zoysiagrass had the lowest rate at $\approx 2 \mathrm{~cm} \cdot \mathrm{d}^{-1}$, whereas bermudagrass had the highest rate at slightly more than $3 \mathrm{~cm} \cdot \mathrm{d}^{-1}$.

In Expt. 2 that compared root extension under different amounts of irrigation (Fig. 2A), there were no significant differences within species among treatments except in zoysiagrass between the $4 \mathrm{~mm} /$ week and $35 \mathrm{~mm} /$ week. Unlike the other species, there was an increasing root extension rate in zoysiagrass with increasing amounts of applied water.

The results in Expt. 3 that also compared root extension under different amounts of irrigation (Fig. 2B) were much like the second experiment. There was no statistical difference in the root extension rate within a species among irrigation treatments. However, the results for zoysiagrass in Expt. 3 showed the same trend as in Expt. 2, i.e., root extension rate increased with increasing amounts of water application. The results for bermudagrass showed a similar trend. In contrast, the greatest root extension rate for St. Augustinegrass was observed in the $4 \mathrm{~mm} /$ week treatment.

Root mass. The measurements of root dry mass at the end of all experiments showed a large difference among the depths of harvest, because root mass declined with soil depth in all species. However, in the experiment with differing frequencies of irrigation (Table 1), there were interesting differences in distribution of mass with depth among species. St. Augustine had the most equal root mass distribution across the three depths with comparatively low root mass in the top layer $(5$ to $30 \mathrm{~cm}$ ) and high root mass in the bottom

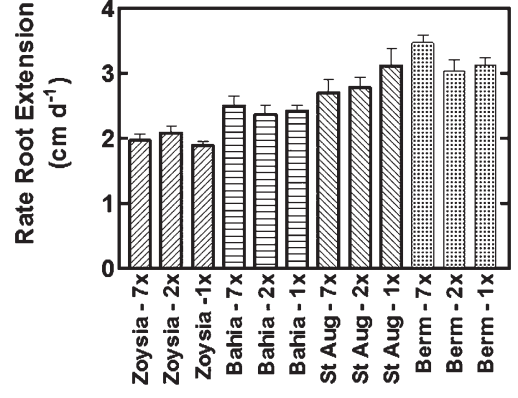

Species \& Frequency per Wk

Fig. 1. Rate of root extension for each turfgrass with treatments of differing frequencies of irrigation: daily $(7 \times)$, twice weekly $(2 \times)$, and once a week $(1 \times)$. The vertical lines for each bar are the SE of the mean. There were no significant differences in root growth rate within a species among treatments.
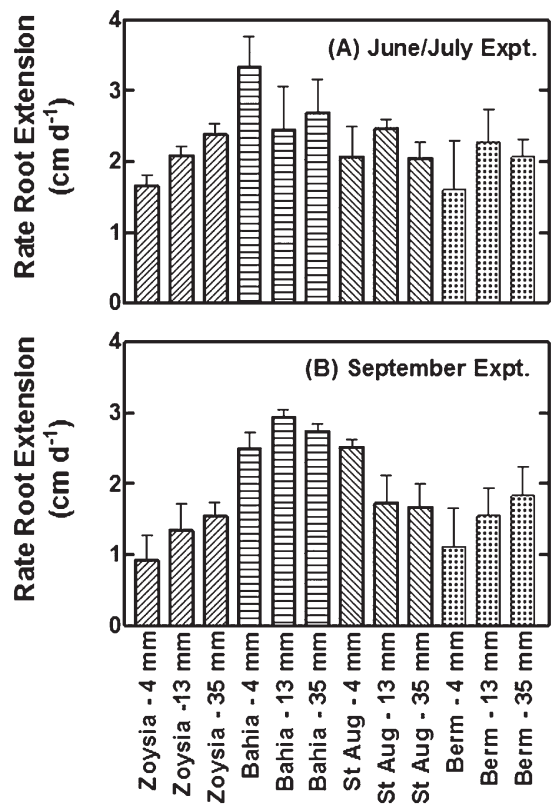

Species \& Amount per Wk

Fig. 2. Rate of root extension in (A) Expt. 2 (June/ July) and (B) Expt. 3 (September) plotted for each turfgrass and differing amount of weekly irrigation treatment. The vertical lines for each bar are the SE of the mean.

layer $(30$ to $60 \mathrm{~cm})$. Bahiagrass had the greatest amount of root mass in the top layer but this amount decreased substantially with each successively deeper layer. Zoysiagrass had the least amount of roots in all layers. In fact, zoysiagrass had very little total root mass below $30 \mathrm{~cm}$. No statistical differences were identified in root mass at any depth within a species among the frequency of irrigation treatments.

Similar to Expt. 1, root mass distribution with depth in Expt. 2 (Table 2) and Expt. 3 (Table 3) showed substantial differences among species. Zoysiagrass and bermudagrass generally had less root mass in all cases than St. Augustine and bahiagrass. Zoysiagrass 
Table 1. Root mass $(\mathrm{g}) \pm$ SEM at the completion of Expt. 1 with various frequencies of irrigation.

\begin{tabular}{lccc}
\hline \multirow{2}{*}{$\begin{array}{l}\text { Root } \\
\text { layer }(\mathrm{cm})\end{array}$} & \multicolumn{3}{c}{ Irrigation frequency } \\
\cline { 2 - 4 } & Weekly & Twice weekly & Daily \\
\hline $5-30$ & $0.70 \pm 0.10$ & $0.70 \pm 0.24$ & $1.22 \pm 0.48$ \\
$30-60$ & $0.16 \pm 0.08$ & $0.14 \pm 0.09$ & $0.22 \pm 0.07$ \\
$60-90$ & $0.01 \pm 0.01$ & $0.02 \pm 0.01$ & $0.07 \pm 0.04$ \\
\multicolumn{4}{c}{ St. Augustinegrass } \\
$5-30$ & $0.98 \pm 0.22$ & $1.25 \pm 0.51$ & $1.05 \pm 0.21$ \\
$30-60$ & $0.41 \pm 0.14$ & $0.57 \pm 0.10$ & $0.68 \pm 0.06$ \\
$60-90$ & $0.57 \pm 0.24$ & $0.49 \pm 0.10$ & $0.52 \pm 0.13$ \\
\multicolumn{4}{c}{} \\
$5-30$ & $2.09 \pm 0.33$ & $2.43 \pm 0.72$ & $1.96 \pm 0.70$ \\
$30-60$ & $0.62 \pm 0.07$ & $0.91 \pm 0.35$ & $0.76 \pm 0.26$ \\
$60-90$ & $0.27 \pm 0.07$ & $0.27 \pm 0.10$ & $0.20 \pm 0.05$ \\
5 & 3 Bermudagrass \\
$5-30$ & $2.02 \pm 0.42$ & $1.88 \pm 0.38$ & $2.58 \pm 0.21$ \\
$30-60$ & $0.63 \pm 0.19$ & $1.04 \pm 0.18$ & $1.03 \pm 0.23$ \\
$60-90$ & $0.45 \pm 0.07$ & $0.46 \pm 0.17$ & $0.66 \pm 0.20$ \\
\hline \multicolumn{3}{c}{}
\end{tabular}

Table 2. Root mass $(\mathrm{g}) \pm$ SEM at the completion of Expt. 2 (June/July) with various amounts of weekly irrigation.

\begin{tabular}{rrcc}
\hline \multirow{2}{*}{$\begin{array}{l}\text { Root } \\
\text { layer }(\mathrm{cm})\end{array}$} & $4 \mathrm{~mm}$ Irrigation amount \\
\cline { 2 - 4 } & \multicolumn{3}{c}{ Zoysiagrass } \\
$5-30$ & $0.15 \pm 0.06$ & $0.38 \pm 0.05$ & $0.86 \pm 0.01$ \\
$30-60$ & $0.04 \pm 0.00$ & $0.21 \pm 0.05$ & $0.29 \pm 0.07$ \\
$60-90$ & $0.01 \pm 0.01$ & $0.17 \pm 0.04$ & $0.25 \pm 0.04$ \\
\multicolumn{4}{c}{ St. Augustinegrass } \\
$5-30$ & $0.79 \pm 0.34$ & $1.25 \pm 0.51$ & $0.98 \pm 0.22$ \\
$30-60$ & $0.68 \pm 0.06$ & $0.57 \pm 0.10$ & $0.41 \pm 0.14$ \\
$60-90$ & $0.52 \pm 0.13$ & $0.49 \pm 0.10$ & $0.57 \pm 0.24$ \\
\multicolumn{4}{c}{ Bahiagrass } \\
$5-30$ & $0.54 \pm 0.09$ & $1.26 \pm 0.18$ & $1.49 \pm 0.13$ \\
$30-60$ & $0.34 \pm 0.05$ & $0.64 \pm 0.11$ & $1.18 \pm 0.46$ \\
$60-90$ & $0.26 \pm 0.09$ & $0.14 \pm 0.02$ & $0.67 \pm 0.33$ \\
\multicolumn{4}{c}{ Bermudagrass } \\
$5-30$ & $0.16 \pm 0.10$ & $0.28 \pm 0.08$ & $0.32 \pm 0.05$ \\
$30-60$ & $0.14 \pm 0.14$ & $0.09 \pm 0.02$ & $0.10 \pm 0.03$ \\
$60-90$ & $0.05 \pm 0.05$ & $0.04 \pm 0.03$ & $0.08 \pm 0.03$ \\
\hline \multicolumn{3}{c}{}
\end{tabular}

Table 3. Root mass $(\mathrm{g}) \pm$ SEM at the completion of Expt. 3 (September) with various amounts of weekly irrigation.

\begin{tabular}{lcrc}
\hline Root & \multicolumn{3}{c}{ Irrigation amount } \\
\cline { 2 - 4 } layer $(\mathrm{cm})$ & $4 \mathrm{~mm}$ & \multicolumn{3}{c}{ 13 mm } & $35 \mathrm{~mm}$ \\
\hline & \multicolumn{3}{c}{ Zoysiagrass } \\
$5-30$ & $0.04 \pm 0.01$ & $0.10 \pm 0.04$ & $0.16 \pm 0.06$ \\
$30-60$ & $0.00 \pm 0.00$ & $0.01 \pm 0.01$ & $0.01 \pm 0.00$ \\
$60-90$ & $0.00 \pm 0.00$ & $0.00 \pm 0.00$ & $0.00 \pm 0.00$
\end{tabular}

St. Augustinegrass

$\begin{array}{llll}5-30 & 0.31 \pm 0.12 & 0.56 \pm 0.22 & 0.34 \pm 0.07\end{array}$

$\begin{array}{llll}30-60 & 0.14 \pm 0.06 & 0.24 \pm 0.14 & 0.09 \pm 0.03\end{array}$

$\begin{array}{llll}60-90 & 0.07 \pm 0.03 & 0.16 \pm 0.13 & 0.01 \pm 0.00\end{array}$

Bahiagrass

$\begin{array}{llll}5-30 & 0.59 \pm 0.05 & 0.89 \pm 0.21 & 0.84 \pm 0.08\end{array}$

$\begin{array}{llll}30-60 & 0.38 \pm 0.045 & 0.63 \pm 0.03 & 0.60 \pm 0.05\end{array}$

$\begin{array}{llll}60-90 & 0.07 \pm 0.04 & 0.26 \pm 0.04 & 0.22 \pm 0.04\end{array}$

Bermudagrass

$\begin{array}{llll}5-30 & 0.18 \pm 0.08 & 0.26 \pm 0.09 & 0.32 \pm 0.08\end{array}$

$\begin{array}{llll}30-60 & 0.05 \pm 0.03 & 0.08 \pm 0.03 & 0.05 \pm 0.02\end{array}$

\begin{tabular}{llll}
$60-90$ & $0.02 \pm 0.01$ & $0.01 \pm 0.01$ & $0.02 \pm 0.01$ \\
\hline
\end{tabular}

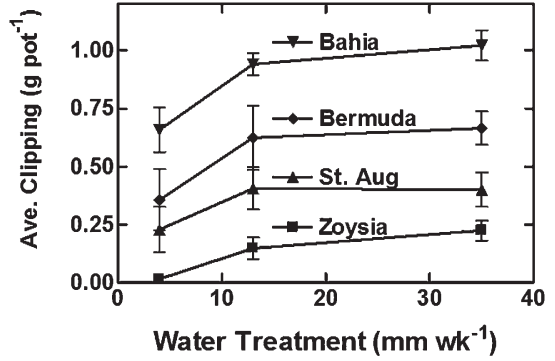

Fig. 3. Clipping mass harvested throughout sod establishment in Expt. 3 from the four grasses when subjected to various irrigation treatments. The bars for each data are the SE of the mean.

and bermudagrass had low amounts of root mass in the deepest soil layer $(60$ to $90 \mathrm{~cm})$ in particular.

In Expt. 2, zoysiagrass required large amounts of irrigation $(35 \mathrm{~mm} /$ week in these experiments) to maximize root mass. In Expt. 3 , there was virtually no mass for zoysiagrass below $30 \mathrm{~cm}$ for any of the irrigation treatments. This result likely reflects the slow root extension rate observed for zoysiagrass in the late-season establishment.

Bahiagrass root mass was decreased with the deficit irrigation of $4 \mathrm{~mm} /$ week in both Expts. 2 and 3 (Tables 2 and 3). However, irrigation of bahiagrass with $13 \mathrm{~mm} /$ week irrigation was sufficient to attain a root mass similar to the well-watered treatment. Irrigation of St. Augustine with $13 \mathrm{~mm} /$ week was sufficient of overcome the low root mass observed in the $4 \mathrm{~mm} /$ week treatment. In fact, there is some indication that $13 \mathrm{~mm} /$ week irrigation was an optimum irrigation for St. Augustine to attain maximum root mass. The highest irrigation treatment for St. Augustine, especially for the late summer experiment (Table 3), appeared to have resulted in suppressed development of root mass.

Clipping mass. The mass of the clippings harvested in Expt. 3 (Fig. 3) showed substantial differences among species. Zoysiagrass had the lowest amount of clippings and bahiagrass the highest. The response in clipping mass to the irrigation treatments was similar for all species. Clipping mass was depressed for all grasses by the $4 \mathrm{~mm} /$ week treatment. No differences in clipping mass within a species were observed between the $13 \mathrm{~mm} /$ week treatment and the $35 \mathrm{~mm} /$ week treatment.

Seasonal changes in root extension. A bonus in these experimental data was the possibility of comparing potential root extension rate during sod establishment at different times of the growing season. The data from the common control-irrigation treatment of $280 \mathrm{~mL}$ once a week ( $35 \mathrm{~mm} /$ week) from the three experiments was used to do this comparison. No seasonal differences in root extension rate were observed for zoysiagrass and bahiagrass (Fig. 4). In contrast, St. Augustine and bermudagrass had much higher root extension rates in the early spring experiment (Expt. 1) than the two experiments performed later in the season.

\section{Discussion}

These experiments were undertaken to examine the two alternate hypotheses that 1) frequent irrigations are needed to stimulate rapid root extension; and 2) deficit irrigation would stimulate rapid root extension to reach layers deep in the soil that might contain stored water. The common recommendation for establishing sod is to irrigate deeply and infrequently for optimal root development (Bennett and Doss, 1960; Doss et al., 1960; Jordan et al., 2003; Madison and Hagan, 1962). The results of Expt. 1 clearly showed that the frequency of irrigation had no impact on the rate of root extension within a species (Fig. 1). Similarly, no differences in root mass at various depths in the soil were observed as a result of frequency of irrigation. These results are consistent with the findings of Peacock and Dudeck (1985) who found no response in St. Augustinegrass root mass or root length density to differing irrigation frequencies in a Florida field study. These results do not demonstrate any need to irrigate the establishing sod of these grasses for root development any more often than once per week. Therefore, the subsequent experiments on the amount of irrigation application were done with applications once per week.

Applications of differing amounts of irrigation also resulted in statistically similar rates of root extension within a species (Fig. 2 ), except with zoysiagrass in Expt. 1 between the 4 and $35 \mathrm{~mm} /$ week application. These results do not indicate any stimulation of root extension rate with deficit irrigation. In fact, there is a slight trend for zoysiagrass and bermudagrass to have greater extension rate at the higher irrigation amounts. Other studies examining warm-season turfgrass root establishment response to irrigation volume are lacking. In a study of three established cool-season grasses, Bastug and Buyuktas (2003) found that deficit irrigation levels of $75 \%$ of Class A Pan resulted in the greatest root weights when compared with plots irrigated to $100 \%, 88 \%$, or $50 \%$ of Class A Pan evaporation.

Differences existed among species in the root mass that developed under the various irrigation amounts (Tables 2 and 3). Zoysiagrass had a progression in increasing root mass with increasing irrigation amounts; bahiagrass showed no further increase in root mass with increasing irrigation from 13 to $35 \mathrm{~mm} /$ week. Although zoysiagrass needs to receive maximum irrigation to achieve the highest root mass, it appears from these tests that $13 \mathrm{~mm} /$ week irrigation was sufficient for bahiagrass to achieve maximum root mass. Neither St. Augustine nor bermudagrass exhibited differences in root mass among the amounts of irrigation so that minimal irrigation appears sufficient to achieve root mass. In no case was there evidence to support the hypothesis that deficit irrigation consistently resulted in greater rooting as measured by mass.

The clipping data collected in Expt. 3 (Fig. 3) helped to focus the impact of deficit 


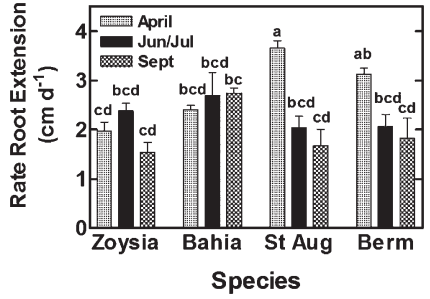

Fig. 4. Rate of root extension plotted for each grass and each treatment of weekly applications of $35 \mathrm{~mm}$ water in the three experiments. The vertical lines for each bar are the SE of the mean. Bars noted with the same letter are not significantly different $(>0.05)$.

irrigation on sod establishment. Irrigation with $13 \mathrm{~mm} /$ week was sufficient to maximize clipping mass for all grasses. Because $13 \mathrm{~mm} /$ week was sufficient irrigation to maximize root establishment in St. Augustine, bahiagrass, and bermudagrass as measured both by extension rate and mass, the results of these experiments indicate that a modest, infrequent deficit-irrigation regime is sufficient for sod establishment.

Zoysiagrass proved to be more delicate in its water needs during sod establishment. Both root extension and root mass were suppressed in the $4 \mathrm{~mm} /$ week treatment as compared with the $35 \mathrm{~mm} /$ week treatment. It is concluded that deficit irrigation is inappropriate for zoysiagrass and that the soil water needs to be periodically fully replenished. Shoot growth of zoysiagrass has previously been shown to be highly sensitive to deficit irrigation (Wherley, 2011).

The comparison of root extension rate at the three times during the growing season allowed by these experiments resulted in some interesting comparisons (Fig. 4). Root extension in zoysiagrass and bahiagrass was essentially the same at all times of the years, indicating that sod establishment in these species can be done without regard to the time of season. This was not the case for St. Augustine and bermudagrass. The much higher root extension rates with the control irrigation treatment observed during Expt. 1 as compared with Expts. 2 and 3 indicate that sod establishment is favored in the spring for these two species. It may be possible that root extension during establishment of St. Augustine and bermudagrass in the spring is favored by low temperatures.

\section{Literature Cited}

Acuna, C.A., T.R. Sinclair, C.L. Mackowiak, A.R Blount, K.H. Quesenberry, and W.W. Hanna 2010. Potential root depth development and nitrogen uptake by tetrapoloid bahiagrass hybrids. Plant Soil 334:491-499.

Bastug, R. and D. Buyuktas. 2003. The effects of different irrigation levels applied in golf courses on some quality characteristics of turfgrass. Irrig. Sci. 22:87-93.

Beard, J.B. 1973. Turfgrass: Science and culture. Prentice-Hall, Englewood Cliffs, NJ.

Bennett, O.L. and B.D. Doss. 1960. Effect of soil moisture level on root distribution of cool-season forage species. Agron. J. 52:204-207.
Doss, B.D., D.A. Ashley, and O.L. Bennett. 1960 Effect of soil moisture regime on root distribution of warm season forage species. Agron. J. 52:569-572.

Fu, J. and P.H. Dernoeden. 2009. Creeping bentgrass putting green turf responses to two summer irrigation practices: Rooting and soil temperature. Crop Sci. 49:1063-1070.

Fu, J., J. Fry, and B. Huang. 2007. Tall fescue rooting as affected by deficit irrigation. HortScience 42:688-691

Jia, J., M.D. Dukes, and J.M. Jacobs. 2009 Bahiagrass crop coefficients from eddy correlation methods in central Florida. Irrig. Sci. 28:5-15.

Jordan, J.E., R.H. White, D.M. Vietor, T.C. Hale, J.C. Thomas, and M.C. Engelke. 2003. Effect of irrigation frequency on turf quality, shoot density, and root length denity of five bentgrass cultivars. Crop Sci. 43:282-287.

Madison, J.H., Jr. and R.M. Hagan. 1962. Extraction of soil moisture by 'Merion' bluegrass (Poa pratensis L. 'Merion') turf, as affected by irrigation frequency, mowing height and other cultural operations. Agron. J. 54: $157-160$.

Marcum, K.B., M.C. Engelke, S.J. Morton, and R.H. Whilte. 1995. Rooting characteristics and associated drought resistance of zoysiagrass. Agron. J. 87:534-538.

Peacock, C.H. and A.E. Dudeck. 1985. Effect of irrigation interval on St. Augustinegrass rooting. Agron. J. 77:813-815.

Qian, Y.L. and J.D. Fry. 1996. Irrigation frequency affects zoysiagrass rooting and plant water status. HortScience 31:234-237.

Wherley, B. 2011. Turfgrass growth, quality, and reflective heat load in response to deficit irrigation practices. In: Evapotranspiration. Leszek Labedzki, Vienna, Austria. In press. 